\title{
A evasão escolar nas representações sociais de professores do ensino fundamental
}

\author{
School evasion in the social representations of elementary school teachers
}

Luciene Alves Miguez Naiff[a], Denis Giovani Monteiro Naiff[b]

\footnotetext{
[a] Professora Adjunta do Departamento de Psicologia da Universidade Federal Rural do Rio de Janeiro (UFRRJ), Rio de Janeiro, RJ - Brasil, e-mail: lunaiff@ hotmail.com

${ }^{[b]}$ Professor Adjunto do Departamento de Psicologia da Universidade Federal Rural do Rio de Janeiro (UFRRJ), Rio de Janeiro, RJ - Brasil, e-mail: dnaiff@ufrrj.br
}

Recebido: $12 / 09 / 2011$ Received: 09/12/2011

Aprovado: 04/10/2012 Approved: 10/04/2012

\section{Resumo}

O universo escolar é atualmente um grande foco de pesquisas nas áreas da educação e da psicologia e vem crescendo, principalmente no Brasil, os estudos que utilizam o referencial da teoria das representações sociais em busca de um melhor entendimento dessa realidade. 0 presente artigo teve o objetivo de identificar e comparar as representações sociais existentes entre 168 professores da rede municipal de ensino das cidades do Rio de Janeiro e de Niterói a respeito da evasão escolar de seus alunos e se estas representações seriam positivadas, negativadas ou neutras, além do provável grau de estereotipia associado a elas. Para levantar as representações sociais, utilizamos um questionário associado a uma tarefa de evocação livre utilizando como termo indutor "Evasão escolar". A comparação entre os dois prováveis núcleos centrais das representações sociais da evasão escolar entre os professores indicam uma representação negativada configurada ao redor da presença de elementos relacionados à estrutura familiar e à desmotivação do aluno como provável estruturação básica compartilhada ao pensamento social docente sobre o assunto estudado.

Palavras-chave: Representação social. Educação. Fracasso escolar.

\begin{abstract}
The school environment is currently a major focus of research in the areas of education and psychology and has been growing, especially in Brazil, the number of studies based on the theory of social representations in search of a better understanding of this reality. This paper aimed to identify and compare social representations between 168 teachers from municipal schools in the cities of Rio de Janeiro and Niterói about school evasion of their students and if these representations were positive, negative or neutral above the likely level of stereotypy associated with them. To raise the social representations, we use a questionnaire associated with a task of free recall using the term inducer as "School evasion". The comparison between the two central nuclei of the likely social representations of school dropouts among teachers indicate a negative representation related to family structure and the lack of motivation of the student as a probable basic structure associated to the teachers'social thinking about this particular subject.
\end{abstract}

Keywords: Social representation. Education. Academic failure

Psicol. Argum. 2014 jul./set., 32(78), 79-88 


\section{Introdução}

A Inclusão Educacional é uma meta nacional que envolve tanto o comprometimento das macropolíticas oficiais para a educação quanto às práticas pedagógicas cotidianas das escolas. A discussão sobre a escola como agente de inclusão ou exclusão social pode ser exemplificada quando nos deparamos com as implicações sociais de dados que mostram que o sistema educacional brasileiro ainda apresenta índices de evasão escolar e defasagem idade/série incompatíveis com os projetos de desenvolvimento da sociedade associados à educação formal. Segundo a Sinopse Estatística da Educação Básica de 2009 (INEP, 2009), o Estado do Rio de Janeiro apresentava em 2008, 16\% de taxa de reprovação dos alunos no ensino básico, com $24,4 \%$ no 6o ano, ou seja, praticamente 1 aluno em cada 4 matriculados no $6^{\circ}$ ano do ensino fundamental era reprovado ao final do ano letivo. Como uma das prováveis conseqüências da reprovação, encontramos no Estado, $3,1 \%$ de taxa de evasão, com $4,7 \%$ no 6 o ano e $5,1 \%$ no 9o ano. No ensino médio as taxas aumentavam em média, para $19,6 \%$ de reprovação e $13,8 \%$ de evasão dos alunos.

Esses dados apontam para a manutenção de um fenômeno social que ganhou na literatura a denominação de "fracasso escolar". Os estudos mostravam que a existência em nosso sistema educacional tanto de excluídos da escola, um conjunto de indivíduos em idade escolar, que deveriam estar freqüentando a escola, mas que por diversos motivos constavam como evadidos; quanto de excluídos na escola, escolares que mesmo estando matriculados e cursando a escola, por força de sucessivas reprovações acusavam forte defasagem idade/série em seus estudos (Patto, 1988, 2010, Ferraro \& Machado, 2002). A pesquisa brasileira a respeito do fenômeno do fracasso escolar se estruturou basicamente ao redor de grandes eixos temáticos (Angelucci, Kalmus, Paparelli \& Patto, 2004), a saber:

a) A análise do fracasso escolar como um problema eminentemente psíquico, com a conseqüente culpabilização das crianças e da família, ou seja, o diagnóstico de uma organização psíquica imatura na criança, que resultaria em ansiedade, dificuldade de atenção, agressividade, entre outros sintomas, gerando problemas psicomotores e inibição intelectual prejudiciais à aprendizagem. Nessa dimensão também se encontram trabalhos que correlacionam a situação de pobreza dos alunos (fator alheio à escola) como causa do insucesso escolar, levando o professor a desenvolver baixas expectativas sobre esse aluno pobre;

b) $\mathrm{O}$ fracasso escolar como um problema técnico, fruto de técnicas de ensino inadequadas ou da falta de domínio correto pelo professor. Aqui, o processo de culpabilização aponta para a figura do professor e apesar de identificar as causas dentro do universo escolar, reduz-se a complexidade de sua produção a uma simples inadequação técnica;

c) 0 fracasso escolar como questão institucional, presente na própria lógica excludente inerente à educação escolar. Nesta dimensão, pensa-se a escola enquanto instituição social seletiva e excludente, sugerindo como possibilidade de enfrentamento do problema políticas educacionais de cunho "progressistas" que transformem o processo avaliativo visando evitar romper a cultura de reprovação presente em nossas escolas, como as propostas dos ciclos de aprendizagem.

Apesar dos inegáveis progressos observados na primeira década do século XXI, fruto dos maiores investimentos feitos na educação, a cultura da reprovação, também denominada na literatura de pedagogia da repetência (Ribeiro, 1991), ainda persiste nas representações e práticas sociais dos atores envolvidos com a educação formal brasileira. Buscando superar esse cenário, em 2010 o Ministério da Educação homologou a recomendação do Conselho Nacional de Educação (CNE) de acabar com a reprovação nos três primeiros anos do ensino fundamental, criando um "Ciclo de Alfabetização e Letramento", em vista da constatação de que muitas crianças ainda continuam sendo reprovadas em seu primeiro ano de estudo no ensino fundamental (Benevides, 2011). Essa recomendação é embasada na proposta teórica-metodológica dos ciclos de aprendizagem empregados no Brasil por algumas secretarias municipais de educação (Mainardes, 1998; 2001; 2006; 2009). Segundo declaração da secretária de Educação Básica do Ministério da Educação, Maria do Pilar Lacerda:

Tivemos um índice de aprovação de 94,9\%, em 2009, o que nos mostra que, de cada cem crianças, cinco ainda são reprovadas logo que ingressam na escola. Pesquisas apontam que, se o aluno é reprovado, dificilmente terá sucesso. A recomendação, que não é lei, é para garantir que todas as crianças 
estejam alfabetizadas até os oito anos" (Benevides, 2011, p. 5).

Dados da literatura também apontam para a correlação direta entre indicadores de reprovação, defasagem série/idade e conseqüente evasão escolar de um contingente significativo das crianças brasileiras, condenadas precocemente a um provável futuro excluído socialmente pela baixa escolaridade formal acumulada (Leon \& Menezes-Filho, 2002). As tentativas de mudanças na pedagogia da repetência no sistema educacional público brasileiro historicamente tem encontrado resistências na classe docente, atores sociais fundamentais no processo educativo (Neves \& Almeida, 1996; Mattos, 2005; Souza, 2006).

Esse ainda é um espinhoso terreno no campo da educação, e um importante fenômeno para a psicologia social voltada ao estudo dos fenômenos escolares, já que as queixas principais docentes refletem um desconhecimento do público alvo que atendem aliado às dificuldades de mudança de um ritmo de trabalho que foi durante muito tempo legitimado e prestigiado. (Fernandes \& Franco, 2001). A Teoria das Representações Sociais (TRS) discute exatamente a necessidade que os atores sociais têm de produzir um conhecimento que lhes sejam confortáveis socialmente e lhes ajudem a entender fenômenos sociais que não lhes pareçam familiares (Roussiau \& Bonardi, 2001).

É no universo sociocultural que estão e são continuamente produzidas as representações sociais. Se quisermos compreender por que uma pessoa se comporta de um jeito e não de outro devemos ver as relações sociais embutidas em seu cotidiano. Nossas reações frente a outras pessoas estão em grande parte mediadas pelas percepções e representações sociais que fazemos delas.

0 universo escolar é atualmente um grande foco de pesquisas nas áreas da educação e da psicologia e vem crescendo, principalmente no Brasil, os estudos que utilizam o referencial da teoria das representações sociais em busca de um melhor entendimento dessa realidade (Alves-Mazzotti, 2005; 2008).

Segundo Gilly (2001) o crescente interesse do estudo das representações sociais na área da educação se deve principalmente à sua relevância social e o quanto mobiliza os atores envolvidos:
Dada a importância crucial que lhe atribuem as diferentes partes envolvidas (administradores, dirigentes centrais, agentes do sistema e usuários) o fracasso escolar e as desigualdades sociais face à escola estão entre os temas que melhor revelam os aspectos centrais das representações que sustentam os diferentes discursos a esse respeito (p.322).

Essas considerações servem para ilustrar como professores e alunos, a partir de algumas informações de origem e natureza diversa, organizam-nas, interpretam-nas, e constroem algumas representações mútuas que irão mediar suas relações.

0 conceito de representação social designa uma forma específica de conhecimento, o saber do senso comum, cujos conteúdos manifestam a operação de processos generativos e funcionais socialmente marcados. Mais amplamente, designa uma forma de pensamento social. Uma definição muito bem aceita dentro do campo de estudos das representações sociais e que resume suas principais características é dada por Jodelet (1984) ao afirmar que:

As representações sociais são modalidades de pensamento prático orientadas para a comunicação, a compreensão e o domínio do ambiente social, material e ideal. Enquanto tais, elas apresentam características específicas no plano da organização dos conteúdos, das operações mentais e da lógica (p.361-2).

Falar em representações sociais implica em considerá-las enquanto emergentes na dimensão simbólica da vida social, pois, tal como afirma acima Jodelet (1984), servem para agir sobre o mundo e sobre os outros. As representações sociais nascem no cotidiano, nas interações que estabelecemos seja na família, no trabalho, na escola, nas relações com a saúde etc, seja onde quer que exista uma realidade a ser apropriada e partilhada. Segundo Moscovici (1984) no cotidiano as pessoas analisam, comentam filosofias de vida não oficiais, que têm um decisivo impacto em suas relações sociais, em suas escolhas, na forma como educam seus filhos, etc. Eventos, ciências e ideologias alimentam as representações sociais, mas informações que chegam, devem sofrer um processo de transformação, para serem apropriadas e utilizadas na vida cotidiana.

Psicol. Argum. 2014 jul./set., 32(78), 79-88 
O objetivo principal de lançarmos mão de representações sociais é buscar compreender o mundo a nossa volta. Os processos responsáveis pela formação das representações sociais são a objetivação e a ancoragem. Isto significa dizer que objetivamos o desconhecido dando-lhe forma tornando-o quase palpável e o ancoramos em nosso próprio sistema de referência pré-existente, utilizando essa estrutura como guia de nossas ações. No entanto, o que se caracteriza como desconhecido, ou usando o termo moscoviciano "não familiar", deve estar associado a um grau suficientemente grande de relevância para um determinado grupo, para que então, possa gerar as conversações e seu conseqüente domínio (Wagner, 1998).

As representações sociais possuem, segundo Abric (1994), uma organização significante, isto é, não são apenas reproduções da realidade, estão imersas em um contexto mais imediato e outro mais global. Respondem a quatro perguntas em sua composição: quem representa? (o sujeito); quando representa? (o momento histórico); a partir de onde representa? (contexto social); e porque representa? (o objetivo) (Jovchelovitch, 1996).

A utilização da teoria das representações sociais como suporte teórico, impõe algumas preocupações com relação à coerência entre o que se pretende estudar (objetos de pesquisa) e o que a teoria oferece (Sá, 1998). Segundo Moscovici (1984), as representações sociais emergem em uma situação social, em função de três condições básicas:

- Dispersão da informação - as informações sobre a escola, seus processos e componentes são ambíguas e produzem uma série de "micro" conhecimentos sobre o assunto, esses micro conhecimentos mantém a informação correta dissolvida gerando dúvidas e incertezas;

- Focalização - a relevância do objeto de representação para o grupo o mantém no foco de interesse para a produção de representações sociais;

- Pressão à inferência - a pertinência e relevância também gera a necessidade de produzir uma representação social sobre um dado objeto que precisa ser compreendido e assimilado pelo grupo.

- 0 estudo das representações sociais se dá no cotidiano, privilegiando a comunicação em sua formação. As representações sociais são produzidas para permitir uma maior adaptação de um determinado grupo a uma realidade que se impõe (Rouquette, 2009).
A formação de representações sociais, portanto, agrega duas principais características de acordo com o que vimos até aqui: em primeiro lugar a premissa de que têm o objetivo de transformar o não-familiar em familiar, e em segundo lugar é uma modalidade, segundo Moscovici (2003) que tem por função direcionar o comportamento e a comunicação.

0 presente artigo possui como objetivo principal identificar e comparar quais as representações sociais existentes entre professores da rede municipal de ensino das cidades do Rio de Janeiro e de Niterói a respeito da evasão escolar de seus alunos, uma das dimensões estruturais do fenômeno do fracasso escolar, e se estas representações seriam positivadas, negativadas ou neutras, além do provável grau de estereotipia associado a elas.

\section{Metodologia}

Este estudo foi aprovado pelo comitê de ética da Universidade Federal Rural do Rio de Janeiro, conforme a resolução CNS/MS, no 196/96. Foram utilizadas na pesquisa, para efeitos comparativos, duas amostras de professores, sendo 84 professores da rede municipal de ensino de Niterói e 84 professores da rede municipal de ensino da cidade do Rio de Janeiro. Para levantar as representações sociais, utilizamos um questionário associado a uma tarefa de evocação livre (Vergès, 2005). Nessa tarefa de evocação livre foi pedido aos indivíduos entrevistados que expressassem espontaneamente cinco palavras ou expressões que lhes viessem imediatamente à lembrança quando apresentávamos o termo indutor "Evasão escolar". Em uma segunda etapa foi pedido que os sujeitos hierarquizassem por grau de importância as palavras ou expressões evocadas anteriormente. Essa técnica combinada tem a vantagem de aproveitar o material bruto nascido da associação livre e o organizar cognitivamente, permitindo uma reavaliação da ordem de evocação, de acordo com a indicação de Abric (2003). No terceiro e último momento foi pedido para que os pesquisados valorizassem as palavras ou expressões evocadas, informando se elas eram na sua percepção positivas (+), negativas $(-)$ ou neutras $(\mathrm{N})$.

O material final foi analisado pela técnica de construção do quadro de quatro casas, e as respostas foram analisadas com o auxílio do programa de computador denominado EVOC $2003 \AA$ que 
combina a freqüência de evocação de cada palavra com sua ordem de evocação, buscando estabelecer o grau de saliência dos elementos da representação em cada grupo (Oliveira, Marques, Gomes \& Teixeira, 2005).

A organização dos dados, seguindo essa orientação, nos oferece quatro quadrantes que irão determinar o provável grau de centralidade das palavras na estrutura da representação social.

A figura 1 representa um esquema de distribuição dos resultados encontrados na evocação dos sujeitos ao termo indutor. Identificam-se como prováveis elementos centrais da representação social os temas localizados no quadrante superior esquerdo, que foram ao mesmo tempo os mais freqüentes e os mais prontamente evocados. Por outro lado, no quadrante inferior direito, estão localizados os elementos claramente periféricos, com baixa freqüência e menos prontamente evocados. Nos outros dois quadrantes, misturam-se elementos que tanto podem constituir uma espécie de "periferia próxima" ao núcleo central, quanto outros mais distantes nessa subordinação estrutural, sendo que o quadrante inferior esquerdo, composto pelos elementos que foram considerados importantes pelos sujeitos apesar de sua baixa freqüência total no corpus de análise, pode ser denominado de zona de contraste. Abric (2003) considera que este quadrante pode tanto "revelar a existência de um sub-grupo minoritário portador de uma representação diferente" (p. 64), como ser apenas composto de elementos complementares da primeira periferia.

As valorações informadas pelos sujeitos foram submetidas a uma análise matemática para extração dos índices de polaridade e de neutralidade, que segundo De Rosa (2003) funcionam como medidas sintéticas de avaliação e atitude implícita no campo representacional. 0 índice de Polaridade (P) é calculado pelo número de palavras positivadas menos às negativadas, dividido pelo numero total de palavras. As palavras positivadas e negativadas tendem a se equivaler na representação social quando o resultado de $\mathbf{P}$ se situa em um intervalo compreendido por $-0.04 \mathrm{e}+0.04$; quando o resultado estiver compreendido pelo intervalo situado entre +0.04 $\mathrm{e}+1$, consideramos a representação positivada; e quando o intervalo se situa entre -0.04 e -1 , consideramos a representação negativada, aumentando seu grau de polaridade conforme o resultado se aproxima dos limiares superiores ou inferiores da escala (+1 ou -1$)$.

0 índice de neutralidade (N) é obtido pelo número de palavras neutras subtraídas da soma do número de palavras positivas somado às negativas, dividido pelo número total de palavras associadas. Quando o resultado de $\mathbf{N}$ se situa em um intervalo compreendido por $-0.04 \mathrm{e}+0.04$, as somas das palavras neutras tendem a serem iguais as positivas e negativas; quando o resultado estiver compreendido pelo intervalo situado entre +0.04 e +1 , consideramos a representação com alta neutralidade; e quando o intervalo se situa entre -0.04 e - 1 , consideramos a representação com baixa neutralidade.

Outra forma de informação interessante diz respeito ao grau de diferenciação no dicionário expresso por cada grupo relativamente aos objetos de representação. Presumindo que em função da maior ou menor articulação lexical e gramatical, um dado objeto de representação é mais ou menos diferenciado por significados, atributos, e evocações, assume-se que a medição derivada da relação entre palavras diferentes e o número total de palavras é um indicador de "estereotipia". Isto aplica-se ao significado alargado do termo estereotipia, devido aos reconhecidos processos cognitivos de sobresimplificação categorial da realidade (De Rosa, 2003).

Ordem média de evocação

Frequência média

\begin{tabular}{|c|c|}
\hline $\begin{array}{l}\text { 1o quadrante } \\
\text { Elementos do Núcleo Central } \\
\text { prontamente evocados + alta frequência }\end{array}$ & $\begin{array}{l}2^{\circ} \text { quadrante } \\
\text { Elementos da } 1^{\text {a }} \text { periferia } \\
\text { tardiamente evocados + alta freqüência }\end{array}$ \\
\hline $\begin{array}{l}\text { 3o quadrante } \\
\text { Elementos de contraste } \\
\text { prontamente evocados + baixa frequência }\end{array}$ & $\begin{array}{l}4^{\mathbf{o}} \text { quadrante } \\
\text { Elementos da } 2^{\mathbf{a}} \text { periferia } \\
\text { tardiamente evocados + baixa freqüência }\end{array}$ \\
\hline
\end{tabular}

Figura 1 - Representação esquemática da distribuição das cognições das representações sociais no modelo de evocação livre

Psicol. Argum. 2014 jul./set., 32(78), 79-88 
Esta medição é derivada da divisão do № de palavras diferentes associadas por cada grupo de sujeitos pelo $\mathrm{n}$ - total de palavras associadas por cada grupo de sujeitos e representado por (Y). Quanto mais próximo do limiar inferior da escala (de 0 a 1 ) for o resultado de $\mathrm{Y}$, maior a provável estereotipia da representação estudada.

\section{Resultados}

Apresentamos neste artigo os resultados oriundos do modelo de quatro casas geradas através da análise das evocações, pela possibilidade esquemática que a técnica proporciona à obtenção de um modelo estrutural da representação social estudada (Sá, 1996).

A figura 2 apresenta a provável estrutura presente nas representações sociais da "Evasão escolar" na educação fundamental pelos professores da rede municipal de educação de Niterói. Olhando para o provável núcleo central dessa representação, presente no quadrante superior esquerdo, encontramos que a desmotivação discente, associada às dificuldades de aprendizagem desse aluno e a estrutura familiar estruturam um conjunto de sentidos provavelmente centrais nas representações sociais desse conjunto docente. Em uma primeira periferia (superior esquerdo) encontramos uma possível inadaptação do aluno à escola como justificativa dada ao fracasso escolar. Sentidos mais relacionados à situação sócio-econômica dos alunos evadidos, normalmente objetivadas na literatura naqueles situados nas camadas mais desfavorecidas de nossa sociedade, encontram-se no quadrante inferior esquerdo: A pobreza econômica que permeia a realidade desse aluno, associado à necessidade dos jovens trabalharem, estruturam uma visão já bastante mapeada na literatura sobre as atribuições de causalidade a que professores possuem a respeito do fracasso de seus alunos (Martini \& Del Prette, 2005). A falta de apoio e o trabalho infantil surgem como elementos periféricos na análise.

A análise de um índice de polaridade e neutralidade nos dá a possibilidade de avanços no entendimento das representações sociais encontradas, ao apontarem medidas sintéticas de avaliação e atitude implícita no campo representacional. A análise mostrou que 95 palavras/frases diferentes foram emitidas pelos sujeitos, perfazendo um total no corpus de análise de 280 palavras/frases. Dessas 280 palavras/frases, 30 foram identificadas pelos sujeitos como neutras, 55 como positivas e 195 classificadas como negativas (uma mesma palavra pode ser avaliada como positiva por um sujeito e neutra ou negativa por outros). A análise do Índice de Polaridade (P) da representação social da amostra docente de Niterói apresenta o resultado de -0.50 , apontando para uma representação negativada da evasão escolar. 0 cálculo do Índice de Neutralidade (N), apresentou o resultado de -0.78 , apontando para uma baixa neutralidade do objeto, fruto da necessidade de posicionamentos dos sujeitos ao objeto da representação social. 0 resultado do Indicie de Estereotipia $(\mathrm{Y})$ encontrado foi de 0.33 , o que

\section{Frequência $\geq 13$ \\ Desmotivação \\ Família}

Dificuldade de aprendizagem
$<2,1$ ordem média de evocação $\geq 2,1$

\begin{tabular}{|c|c|c|c|c|c|}
\hline \multicolumn{6}{|c|}{ Frequência < 13} \\
\hline & $\mathrm{n}$ & & & $\mathrm{n}$ & \\
\hline Pobreza & 12 & 2,08 & Falta de apoio & 6 & 2,67 \\
\hline Trabalho & 12 & 1,67 & Trabalho infantil & 5 & 3,00 \\
\hline Exclusão & 6 & 1,83 & & & \\
\hline Distância & 5 & 1,40 & & & \\
\hline Realidade & 5 & 1,80 & & & \\
\hline
\end{tabular}

Figura 2 - Representação social da Evasão escolar para professores da rede pública da cidade de Niterói (n=84) 
indica que essa representação eliciada é bastante estereotipada.

Olhando agora para a estrutura das representações sociais dos professores da cidade do Rio de Janeiro sobre a "evasão escolar" presente na figura 3 , encontramos como prováveis elementos centrais as condições estruturais sócio-econômicas desfavoráveis dos alunos como causadoras do fenômeno do fracasso escolar, associadas à dimensão familiar pouco comprometida com a educação, gerando desinteresse e desmotivação com o processo educacional. Como elementos periféricos presentes na zona de contraste (quadrante inferior esquerdo), cabe destaque o cenário de violência que tem acompanhado a história da cidade do Rio de Janeiro nas últimas décadas, caracterizada por forte espacialização geográfica, e que por impactar prioritariamente as camadas mais empobrecidas da população, surge como importante co-fator associado a uma trajetória de fracasso escolar, especialmente de meninos negros pobres (Carvalho, 2003; 2004; Brito, 2006). Como elementos claramente periféricos aparecem, refletindo o fracasso escolar como questão institucional, alusão a uma escola desinteressante, basicamente associada à rede pública de ensino.

A análise das evocações mostrou que 66 palavras/frases diferentes foram emitidas, perfazendo um total no corpus de análise de 227 palavras/frases, às quais 21 foram identificadas pelos sujeitos como neutras, 24 como positivas e 183 haviam sido classificadas como negativas. A análise do Índice de Polaridade (IP) da representação social da amostra docente do Rio de Janeiro apresenta o resultado de -0.70 , apontando para uma representação mais negativada que em relação à representação encontrada na amostra de Niterói. 0 cálculo do Índice de Neutralidade $(\mathrm{N})$, apresentou o resultado de -0.81 apontando para uma baixa neutralidade do objeto. 0 resultado do Indicie de Estereotipia (Y) de 0.29 indica que a representação apresenta pouca dispersão léxica, o que caracterizaria, similarmente à amostra de Niterói, grande estereotipia da representação social estudada.

As representações sociais dos professores de Niterói e Rio de Janeiro têm alguns pontos em comum, mostrando que o discurso socialmente partilhado acerca dos alunos das escolas públicas circula para além de limites geográficos. Tanto os professores das escolas de Niterói quanto do Rio de Janeiro apontam a família e a desmotivação como elementos importantes ao se pensar em evasão para esse público alvo. 0 grupo de professores de Niterói apresenta ainda a dificuldade de aprendizagem e o grupo de professores do Rio de Janeiro vincula os elementos desinteresse, trabalho e pobreza para a idéia da evasão.

Não é de hoje que a família, em especial a família pobre, deixa de ser vista como uma solução para a criação de crianças adequadas a sociedade. Esse fator, construído desde os tempos do higienismo no Brasil, ganhou força com a criação dos chamados internatos ou colégios internos, que para os pobres ficou conhecido também como Funabens, Febens, etc. (Rizzini, Rizzni, Naiff \& Baptista, 2007). Internar os filhos era visto como solução diante da contínua constatação, dada pelos operadores de

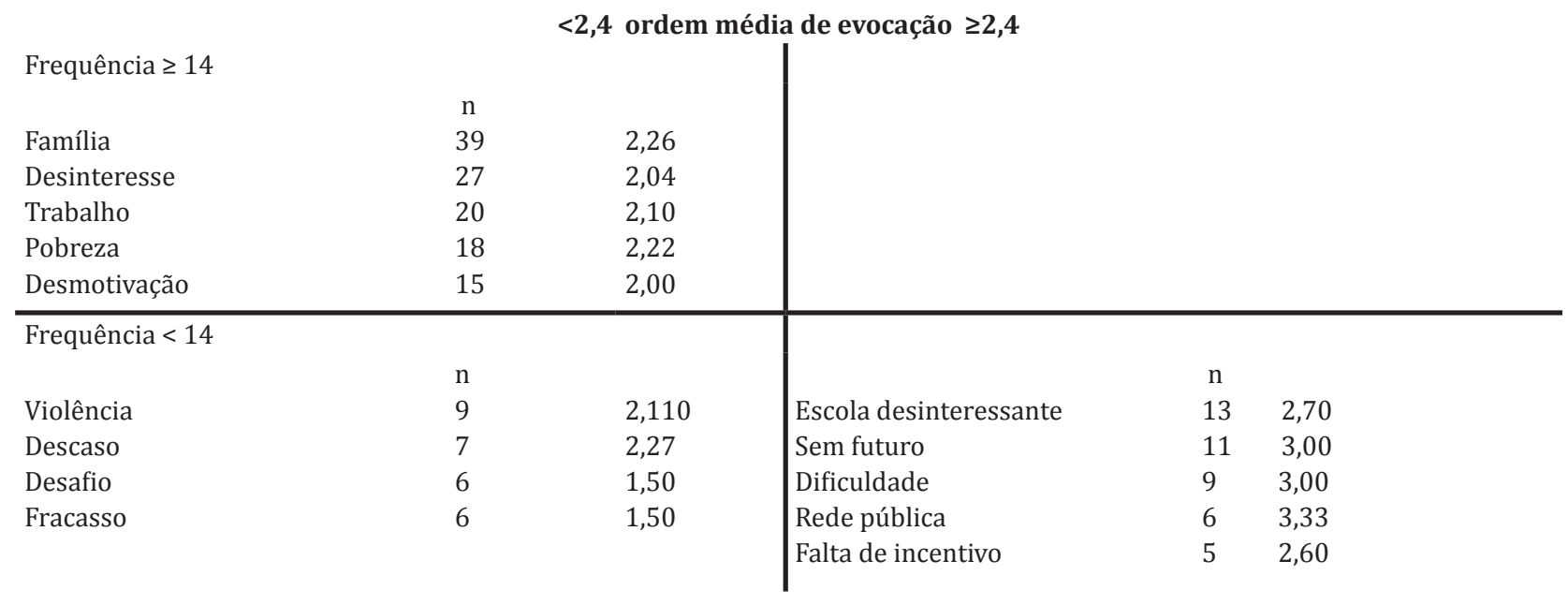

Figura 3 - Representação Social da Evasão escolar para professores da rede pública da cidade do Rio de Janeiro ( $\mathrm{n}=84$ )

Psicol. Argum. 2014 jul./set., 32(78), 79-88 
direito à família pobre, que sua situação era danosa a formação de uma criança. As crianças vindas de lares irregulares, perniciosos, inadequados e, o termo mais atual e na moda, desestruturados, deveriam receber a tutela do Estado e serem protegidas para se tornarem cidadãos dignos. Essa visão deturpada da família pobre atingiu e atinge ainda nos dias de hoje as representações sociais dessa parcela da sociedade. Tudo que não dá certo na vida dos filhos é culpa da família que em última análise, na visão conservadora de determinados grupos sociais nem filhos deveria ter, dada sua situação sócio-econômica. Com a evasão escolar não seria diferente. 0 aluno evade porque a família de alguma forma permite que isso ocorra.

0 elemento marcante e comum entre os grupos, a desmotivação, mostra um outro aspecto da questão. 0 aluno desmotivado pode ser um aluno inteligente que não encontrou na escola um espaço que estimula sua potencialidade ou pode ser um aluno que traz sua desmotivação com os estudos de fora para dentro da escola. Essa última leitura se coaduna melhor com os outros elementos apresentados pelos grupos, quais sejam: dificuldade de aprendizagem, pobreza, trabalho e desinteresse. Para os professores, o aluno tem, aliada a família que não favorece sua permanência na escola, a sua desmotivação pelo mundo da educação formal. Por essa ótica, a permanência na escola com tantos obstáculos demonstra uma capacidade de superação ou resiliência de alguns poucos alunos que transformam a conclusão dos estudos formais em exceções daqueles mais determinados.

Dessa forma, podemos perceber que o discurso ainda passa pela tentativa de encontrar os motivos para a evasão fora da escola. Mantendo uma linha de pensamento que tira do sistema escolar sua parcela de culpa, se mantém uma prática que não precisa se rever (Patto, 1988, 2010, Ferraro $\&$ Machado, 2002). Devemos certamente ultrapassar a "caça as bruxas" em que o aluno, a família e a escola são vistos e responsabilizados sozinhos por qualquer situação que ocorra no ambiente educacional (Angelucci, Kalmus, Paparelli \& Patto, 2004).

Uma visão tão compartimentada gera políticas também compartimentadas e o cerne da questão está exatamente na superação das dicotomias e no envolvimento de todos no processo cotidiano de escolarizar as nossas crianças. 0 levantamento das representações sociais permite visualizar também possíveis práticas que irão manter com elas uma coerência. Nesse sentido, o campo de estudos da educação no Brasil pode se beneficiar dos conhecimentos que a psicossociologia fornece ao identificar o saber que um grupo social partilha sobre um dado fenômeno, entendendo ter esse um poder de eliciar comportamentos e sentimentos.

\section{Considerações finais}

A questão da repetência no ensino fundamental e médio brasileiro continua sendo uma "chaga" que dificulta as possibilidades de desenvolvimento geral da população e leva a indicadores de evasão escolar que transformam a situação, apelando para uma licença poética, numa tragédia social. Essas questões que configuram parte do fenômeno conhecido como "fracasso escolar" basicamente se estruturam ao redor das camadas economicamente menos favorecidas de nossa sociedade, obrigadas a freqüência em um sistema público de ensino que ainda mantém uma estrutura escolar caracterizada por uma cultura política e pedagógica de exclusão e seletividade, qualidade de ensino deficiente e incapaz de gerar respostas eficazes aos desafios gerados pelas especificidades que sua clientela e a realidade brasileira historicamente lhe apresentam.

A comparação entre os dois prováveis núcleos centrais das representações sociais da evasão escolar entre os professores de Niterói e Rio de Janeiro, indicam algumas reflexões: a presença de elementos relacionados à estrutura familiar e à desmotivação do aluno como provável estruturação básica compartilhada ao pensamento social docente sobre o assunto estudado, fato que associado à ausência de elementos críticos relacionados à escola e à prática docente caminham na direção apontada por AlvesMazzotti (2008) ao afirmar que os professores tendem a atribuir o fracasso escolar a condições sócio-psicológicas do aluno e de sua família, eximindo-se de prováveis responsabilidades sobre esse fracasso, o que de certa forma implicam, na visão de Arroyo (2000), no fato de que

a medida que vamos nos aproximando da estrutura e ossatura da escola e de nosso sistema escolar, vamos percebendo com maior nitidez como seu caráter excludente se mantém quase inalterado 
resistindo às reformas, inclusive as mais progressistas, por que está legitimado na cultura política e pedagógica da exclusão, da seletividade, da reprovação e retenção (p.35).

Em se tratando de uma pesquisa em que o embasamento teórico utilizado nos remete ao conhecimento compartilhado no cotidiano dos grupos sociais e a pressão que esse conhecimento exerce nas práticas, não há como ignorar que as representações sociais produzidas pelos professores de ambos os grupos, podem interferir diretamente na forma em que esses indivíduos irão se comportar diante de tal fenômeno escolar.

Portanto, conhecer as representações sociais dos professores acerca da evasão escolar é uma valiosa colaboração da psicologia social e, em última análise, da teoria das representações sociais no entendimento de fenômenos da área da educação. Políticas e ações, mesmo que imbuídas de boas intenções, devem sempre ouvir os sujeitos envolvidos para que possam lograr sucesso em uma perspectiva democrática e de respeito a todos em prol da melhoria da qualidade de vida de nossos concidadãos.

\section{Referências}

Abric, J.-C. (1994). Les reprèsentations sociales: aspects theòriques. In J.-C Abric (Org.), Pratiques sociales et reprèsentations (pp. 11-35). Paris: Presses Universitaires de France.

Abric, J.-C. (2003). Abordagem estrutural das representações sociais: desenvolvimentos recentes. In P. H. F. CAMPOS \& M. C. S. LOUREIRO (Orgs.). Representações sociais e práticas educativas (pp. 35-56). Goiânia: Editora da UCG.

Alves-Mazzotti, A. J. (2005). Representações sociais e educação: a qualidade da pesquisa como meta política. In D. C. Oliveira \& P. H. Campos (Orgs.). Representações sociais, uma teoria sem fronteiras (pp. 141-150). Rio de Janeiro: Museu da República.

Alves-Mazzotti, A. J. (2008). Representações sociais: aspectos teóricos e aplicações à educação. Revista Múltiplas Leituras. 1(1), p. 18-43.

Andrada, E. G. C. (2005). Novos paradigmas na prática do psicólogo escolar. Psicologia: Reflexão e Crítica, 18 (2), p. 196-199.
Angeluci, C. B.; Kalmus, J.; Paparelli, R.; Patto, M. H. S. (2004). 0 estado da arte da pesquisa sobre o fracasso escolar (1991-2002): um estudo introdutório. Educação e Pesquisa. 30(1), p. 51-72.

Arroyo, M. G. (2000). Fracasso/sucesso: um pesadelo que pertuba nossos sonhos. Em Aberto, 17(71), p.33-40.

Benevides, C. (2011, 14 fevereiro). MEC recomenda que escolas deixem de reprovar. Jornal O Globo, p. 5.

Brito, R. S. (2006). Intrincada trama de masculinidades e feminilidades: fracasso escolar de meninos. Cadernos de Pesquisa. 36(127), p. 129-149.

Carvalho, M. P. (2003). Sucesso e fracasso escolar: uma questão de gênero. Educação e Pesquisa. 29(1), 185-193.

Carvalho, M. P. (2004). 0 fracasso escolar de meninos e meninas: articulações entre gênero e cor/raça. Cadernos Pagu. 22, p. 247-290.

De Rosa, A. S. (2003). Le "réseau d'associations". Une technique pour détecter La structure, les contenus, les indices de polarité, de neutralité et de stéréotypie du champ sémantique liés aux représentations sociales. In J.-C. Abric (Org.). Méthodes d'étude des représentations sociales (pp.81-118). Paris: Érès.

Ferraro, A. R.; Machado, N. C. F. (2002). Da universalização do acesso à escola no Brasil. Educação e Sociedade. XXIII (79), p. 213-241.

Gama, E. M. P.; Lucas, L. O.; Salviato, M. L.; Jesus, D. M.; Carvalho, J. M.; Doxsey, J. R. (1991). As percepções sobre a causalidade do fracasso escolar no discurso descontente do magistério. Revista Brasileira de Estudos Pedagógicos. 72(171), p. 356-384.

Gilly, M. (2001). As representações sociais no campo da educação. In D. Jodelet (Org.). As representações sociais (pp.321-342). Petrópolis: Vozes.

Gouvêa, G. F. P. (2000). Um salto para o presente: a educação básica no Brasil. São Paulo em Perspectiva. 14(1), p. 12-21.

Instituto Nacional de Estudos e Pesquisas Educacionais INEP (2009). Sinopse Estatística da Educação Básica 2009. Recuperado em 25 janeiro 2011, de http//: www.inep.gov.br/Basica/Censo/Escolar/Sinopse/ sinopse.asp.

Psicol. Argum. 2014 jul./set., 32(78), 79-88 
Jodelet, D. (1984). Représentation sociale: phénomènes, concept et théorie. In S. Moscovici (Org.). Psychologie sociale (pp. 357-378). Paris: Presses Universitaires de France.

Jovchelovitch, S. (1996). In defence of representations. Journal for the Theory of Social Behaviour. 26(2), 121-136.

Leon, F. L. L.; Menezes-Filho, N. A. (2002). Reprovação, avanço e evasão escolar no Brasil. Pesquisa $e$ Planejamento Econômico. 32(3), p. 417-451.

Mainardes, J. (1998). A promoção automática em questão: argumentos, implicações e possibilidades. Revista Brasileira de Estudos Pedagógicos, 79(192), p.16-29.

Mainardes, J. (2001). A organização da escolaridade em ciclos: ainda um desafio. In C. FRANCO (Org.). Avaliação, ciclos e promoção na educação (pp.70-97). Porto Alegre: Artmed.

Mainardes, J. (2006). Organização da escolaridade em ciclos no Brasil: revisão da literatura e perspectivas para a pesquisa. Educação e Pesquisa, 32(1), 11-30.

Mainardes, J. (2009). A pesquisa sobre a organização da escolaridade em ciclos no Brasil (2000-2006): mapeamento e problematizações. Revista Brasileira de Educação, 14(40), 7-23.

Martini, M. L.; Del Prette, Z. A. P. (2002). Atribuições de causalidade para o sucesso e o fracasso escolar dos seus alunos por professoras do ensino fundamental. Interação em Psicologia, 6(2), p. 149-156.

Mattos, C. L. g. (2005). 0 conselho de classe e a construção do fracasso escolar. Educação e Pesquisa, 31 (2), 215-228.

Moscovici, S. (1984). The phenomenon of social representation. In R. Farr \& S. Moscovici. Social representations (pp.3-70). Cambridge University Press

Moscovici, S. (2003). Representações sociais: Investigações em psicologia social. Petrópolis: Vozes.

Neves, M. B. J.; Almeida, S. F. C. (1996). O fracasso escolar na $5^{\text {a }}$ série, na perspectiva de alunos repetentes, seus pais e professores. Psicologia: Teoria e Pesquisa, 12(2), 147-156.

Oliveira, D. C.; Marques, S. C.; Gomes, M. T.; Teixeira, M. C. T. V. (2005). Análise das evocações livres: uma técnica de análise estrutural das representações sociais. In A. S. P. MOREIRA; B. V. CAMARGO; J. C. JESUÍNO \& S. M. NÓBREGA (Orgs.), Perspectivas teórico-metodológicas em representações sociais (pp. 573-603). João Pessoa: Editora da UFPB.
Patto, M. H. S. (1988). O fracasso escolar como objeto de estudo: Anotações sobre as características de um discurso. Cadernos de Pesquisa, 65, 72-77.

Patto, M. H. S. (2010). A produção do fracasso escolar: histórias de submissão e rebeldia. São Paulo: Casa do Psicólogo (Originalmente publicado em 1990).

Rouquete, M. L. (2009). Qu'est-ce que La pensée sociale? In M. L. ROUQUETTE (Org.), La pensée sociale: perspectives fondamentales et recherches appliquées (pp.5-10). Páris: Érès.

Roussiau, N.; Bonardi, C. (2001). Les représentations sociales. Etat des lieux et perspectives. Sprimont: Mardaga.

Ribeiro, S. C. (1991). A pedagogia da repetência. Estudos Avançados, 12 (5), p. 7-21.

Sá, C. P. (1996). Núcleo Central das representações sociais. Petrópolis,RJ: Vozes.

Sá, C. P. (1998). A construção do objeto de pesquisa em representações sociais. RJ: Eduerj.

Souza, D. T. R. (2006). Formação continuada de professores e fracasso escolar: problematizando o argumento da incompetência. Educação e Pesquisa. 32 (3), p. 477-492.

Sposati, A. (2000). Exclusão social e fracasso escolar. Em Aberto. 17 (71), p. 21-32.

Vergès, P. (2005). A evocação do dinheiro: um método para a definição do núcleo central de uma representação. In A. S. P. MOREIRA; B. V. CAMARGO; J. C. JESUÍNO \& S. M. NÓBREGA (Orgs.), Perspectivas teórico-metodológicas em representações sociais (pp. 471488). João Pessoa, Editora UFPB.

Wagner, W. (1998). Sócio-gênese e características das representações sociais. In A. S. P. MOREIRA \& D. C. OLIVEIRA (Orgs.), Estudos interdisciplinares de representação social (pp.3-25). Goiânia: AB Editora. 